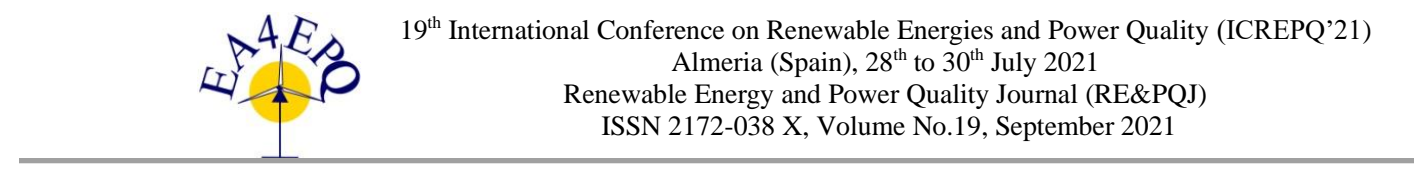

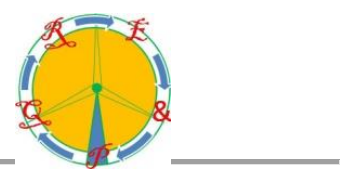

\title{
Energy planning tools applied into urban photovoltaic: the importance of compatibilizing with the constructions
}

\author{
B. B. Freitas ${ }^{1}$, L. F. C. Castro ${ }^{1}$ and P. C. M. Carvalho ${ }^{1}$ \\ ${ }^{1}$ Department of Electrical Engineering \\ Federal University of Ceará \\ Campus Pici - Fortaleza, Ceará (Brazil) \\ e-mail: brenobf93@gmail.com, leocajuaz@gmail.com, carvalho@dee.ufc.br
}

\begin{abstract}
The necessity for an efficient way to develop energy planning in urban environments is increasingly part of the reality of cities. In this sense, tools with the ability to evaluate the installation of distributed generation systems become widely necessary for the elaboration of efficient projects. In this sense, our article aims to evaluate 20 tools from the point of view of urban photovoltaic (PV) planning, considering functionalities such as simulation, scenario generation, bottom-up, availability and application in urban PV; $\mathrm{PV}$ is the most widespread power plant in urban environments, with great dissemination capacity.
\end{abstract}

Key words. energy planning, urban planning, energy tools, Urban PV, photovoltaic.

\section{Introduction}

The great interest for renewable sources for electricity generation and the considerable growth in their use has gained prominence in the world scenario. In this aspect, photovoltaic (PV) power stands out for its great expansion, especially in urban environments, where distributed generation (DG) predominates. According to the International Renewable Energy Agency (IRENA) [1], in 2010 the world's installed capacity was 40,28 GW and in 2019 was 578,55 GW. In Brasil, in 2010, $30 \mathrm{~kW}$ of installed PV power was registered, according to the Agência Nacional de Energia Elétrica (ANEEL) [2]; in February 2021 there was 4,67 GW installed in DG, according to the Associação Brasileira de Energia Solar (ABSOLAR) [3]. Due to the ease of installation of PV systems on roofs of various types of urban buildings, the available area becomes a determining factor for the growth and expansion of DG PV systems. Recent studies associate the demand characteristics for energy with the urban space inserted and propose models of integration between energy and urban planning in order to reduce energy consumption, making it more efficient $[4 ; 5]$. Taking this need into consideration, the search for decentralized energy systems with greater integration of renewable sources and energy demand control strategies bring the concept of Intelligent Energy Systems (IES). The complexity of transition to IES is directly related to the planning capacity integrating urban and energy issues, knowing that each has its particularities and this implies several aspects that should be considered separately [6]. According to these needs, [7] classified 13 tools in the different phases of planning: geographic models for assessing the spatial location of resources, energy models for the construction of consumer demand curves before the DG scenarios and models for evaluating energy aspects. In [8] 12 tools were classified according to their level of application, being multi-scale, district and regional. In [9] 14 models were classified according to their ability to provide services and energy planning in DG. In [10], it is stated that $90 \%$ of the tools are not able to simulate full energy planning when applied to generation by renewable source. In [11] 17 tools with the capacity to evaluate electricity systems in an urban construction sector were presented. Starting from the necessity to evaluate tools that can develop urban PV energy planning, in the present study we evaluated 20 computational tools to analyze its functionalities considering five criteria, being the ability to simulation, scenario projection, bottom-up, payment need and urban PV application. Additionally of classifying the tools according to the criteria, we analyze Building Applied Photovoltaics (BAPV) and Building Integrated Photovoltaics (BIPV) in the tools, according to the articles used as the basis of the research, aiming to provide a critique of integration capacity BAPV and BIPV of urban PV planning tools. The article is divided into 5 sections. The introduction is in section I. Section II presents the methodological review used in the research. Section III discusses the tools analyzed. Section IV brings the results and discussions and Section $\mathrm{V}$ the conclusions. 


\section{Review Methodology}

Initially, a bibliographic review was carried out in the bases Science Direct, Scopus, IEEE Xplore, Google Scholar and Researchgate to find articles that study and/or apply energy planning tools and their respective applications with PV systems. In addition, a search was made for tools capable of analyzing energy planning and that were not contemplated in the articles obtained.

Fig. 1 shows the initial number of papers collected and classified according to exclusion, inclusion and duplication criteria.

\section{Status}

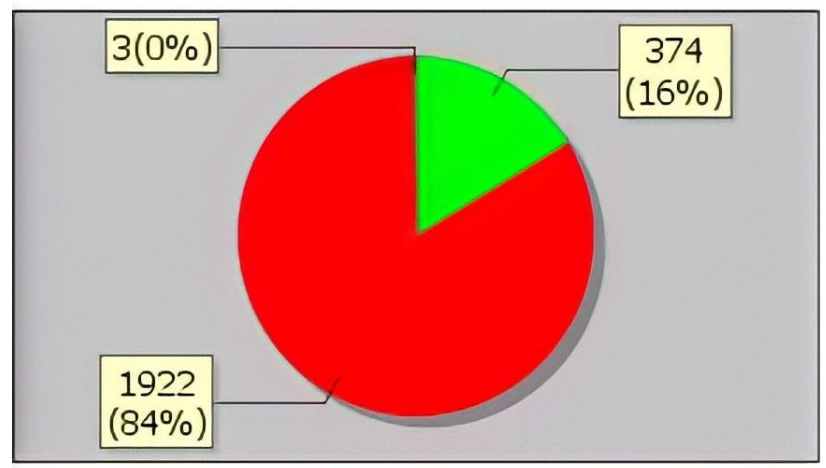

- Accepted O Rejected - Duplicated

Fig. 1. Accepted, rejected and duplicated papers

After this first classification, the abstract of the accepted articles was read in order to identify those that have greater convergence to answer the proposed issues in this study. In this phase, a new classification was created, creating the prioritization for full reading of the articles. In addition, papers were excluded dealing specifically with rural applications, direct application of artificial intelligence technology and studies specifically applied to the evaluation and feasibility phases. Still during this phase two forms of use of PV systems were identified, described in the literature as BAPV and BIPV. The first refers to the PV system being sized and installed after construction is already ready and in operation and the second to the case where the system is designed in conjunction with the construction, being sized more precisely according to the site characteristics and using construction elements already adapted to receive the installation [12].

After the application of evaluation methodology, 65 articles are identified and reclassified with reading priority as shown in Fig. 02. From these results, 20 tools were identified that can be used to assess the PV potential in urban environments. The applied classification was based on 04 features defined to facilitate the distinction between energy planning programs and in addition, the availability of each tool was considered: free access, educational/commercial version or paid.

The first functionality refers to the ability of the simulation tool, i.e., whether it allows simulating the operation of a power system and its ability to meet a certain demand.

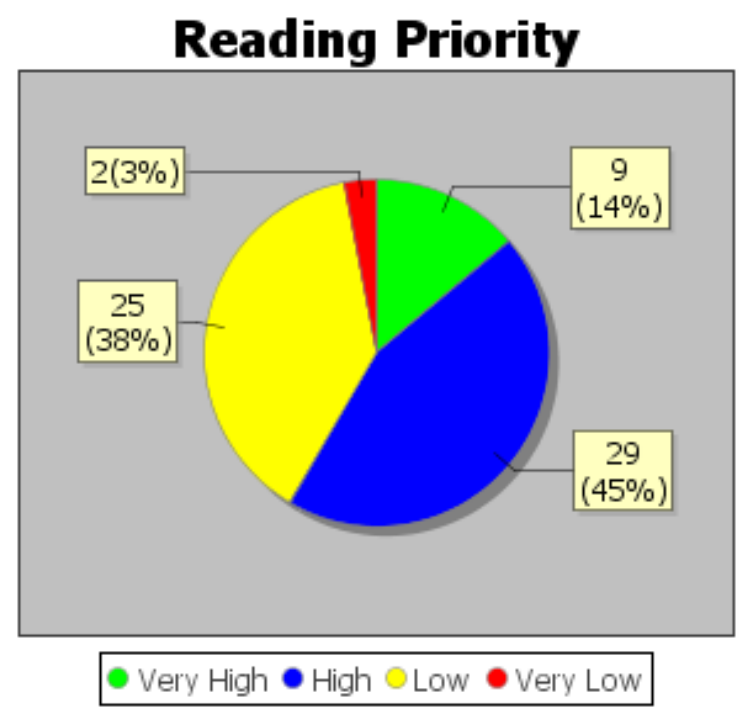

Fig. 02 - Reclassification with read prioritization.

The second functionality concerns scenario generation, i.e., whether it allows to evaluate scenarios in time series, which can be defined by the user and combined at different intervals.

The third functionality is bottom-up, i.e. whether the tool is able to identify and analyze a specific type of energy technology, identifying alternatives and investment possibilities.

The fourth functionality refers to the capacity of urban PV energy planning, i.e., whether the programs can evaluate a PV generation system on roofs of houses, buildings and urban constructions in general.

The evaluation begins considering the tools adopted for energy planning. From this, the applicability of the same in urban environments is evaluated. Those excluded at this stage do not compose the work. This evaluates the scaling capacity and then whether the tool has an urban PV application. After this selection, it is identified which have free access and which are paid.

The diagram shown in Fig 3 represents the steps taken in the programs evaluation, from the most general classification to the most specific.

\section{Tools Evaluated}

According to the criteria evaluated in the selected articles, 20 tools were identified that deal with energy planning and that are within the scope of the present study.

Thus, using both selected articles and handbooks, the main characteristics of the tools were identified and listed.

\section{A. Analyzed Tools}

Balmorel assists in the modeling of energy systems with an emphasis on cogeneration. The tool allows the evaluation of both regional and national energy systems, develops long- and short-term scenarios and has the capacity to simulate PV energy projects. It is an open source model for free download. However, it is formulated in the GAMS language, which requires a commercial license [13]. 


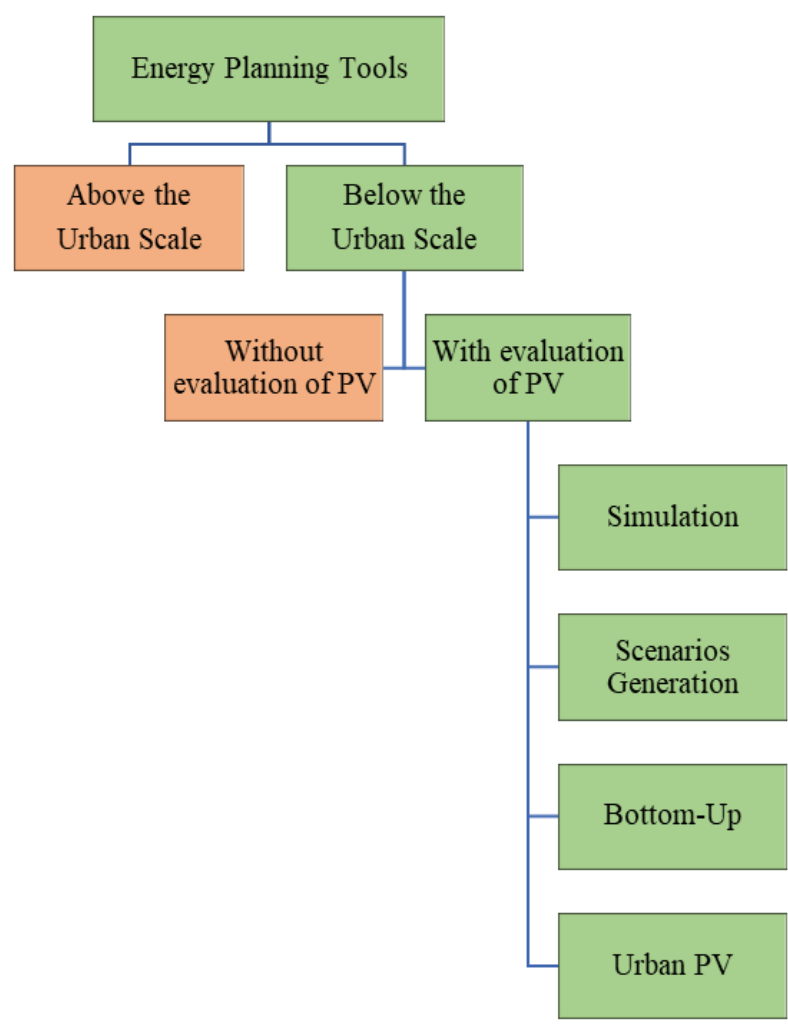

Fig 3. Tools evaluation methodology diagram

CEA (City Energy Analyst) was developed at ETH Zurich and is open source free software. The software is used in theoretical and real case studies to classify energy consumption in urban districts, to optimize energy production [14] and to model off-grid PV projects.

Dieter (Dispatch and Investment Evaluation Tool with Endogenous Renewables) was developed to study flexibility options for the introduction of Renewable Energy Sources (RES). The model, through projectable scenarios, defines combinations that minimize energy generation costs and provide demand management. The program is an open source system, although a paid GAMS license is required to run it [15].

Distritc ECA was developed by the Fraunhofer Institute for Construction Physics in conjunction with the IEAECBCS Annex 51 to efficiently assess electricity supply and demand strategies. The software is free, but with the requirement of a preliminary registration [16], and comprises a set of features with simulation and scenario creation capabilities. The program's premise is to be a tool to conduct a monthly assessment of a district's energy balance.

EnergyPLAN is a deterministic software developed at the Department of Development and Planning at the University of Aalborg that assists in the elaboration of national energy planning strategies based on simulation of scenarios with technical and economic analyzes and can be downloaded through a preliminary record [17]. The program is used to assess the relevance of RES in the national electricity generation matrix.

EnergyPRO was developed by the Danish company EMD International S/A to perform technical-economic analysis and efficiency of energy projects with electricity supply from several production units. The program is paid and can analyze scenarios considering district heating, cogeneration and refrigeration, and also in projects that include geothermal energy, urban PV, wind farms, solar collectors, pumping stations and the like [18].

GridLAB-D is a free open source modeling tool that can be integrated with other modules to increase its resources, developed by Pacific Northwest National Laboratory [19]. The program is designed to model energy systems together with adjacent systems, such as DG technologies, as well as being able to create scenarios to evaluate performance and projections, as well as to model PV systems.

HOMER PRO was developed at the USA National Renewable Energy Laboratory to assist in the modeling of micro-energy systems and to facilitate the comparison between electric power generation technologies in different applications [20]. The tool is paid and has the ability to simulate the behavior of the micro energy system and optimization in the simulation to satisfy the Net Present Value (NPV) restrictions.

HUES (Holistic Urban Energy Simulation) is an open source platform with resources to assist in the design and control of DG systems [21]. The platform aggregates a series of models for simulation and optimization of energy systems in buildings and districts, databases of aggregated annual heat demand and PV potential in Switzerland.

iHOGA (Improved Hybrid Optimization by Genetic Algorithm) was developed at the University of Zaragoza and is focused on the simulation and optimization of autonomous hybrid systems based on RES, such as PV for urban environments. The program has a free educational version for download [22], but much more limited than the full version, with requirements related to the Internet connection.

INSEL (Integrated Simulation Environment Language) was developed by the Faculty of Physics at the University of Oldenburg as a free system for block diagram simulation in applications with RES. The program has ready-made simulation models seeking agility in the initial phases of the modeling, such as the urban PV dimensioning, but the user can design completely new models. In addition, the tool also offers an interface with libraries such as Fortran and C / C ++ [23].

Oemof (Open Energy Modeling Framework) is a modular tool used for modeling and optimization of energy systems. The program is based on the open source programming language Python 4 and based on programming codes made available by users. The program has the ability to assess RES separately, such as urban PV [24].

OSeMOSYS (Open Source Energy Modeling System) is an open source program used for long-term energy assessment and planning. It is freely available for download and the most widely used interface is LEAP commercial software, maintained by the Stockholm Environment Institute and used as a decision-making aid with data management, reports and medium / long-term assessment of scenarios [25].

RETScreen is a clean energy management system developed by Natural Resources Canada [26]. Currently, the tool has a free and a paid version based on Excel and Windows, differentiated in the level of detail of the project. In such a way, any scale system can be modeled and different scenarios can be developed, considering energy efficiency measures, several electric and thermal 
power plants, integration with FER, hybrid systems and the like.

SIREN (SEN Integrated Renewable Energy Network) is a modeling toolkit developed by the Australian organization Sustainable Energy Now, being made available free of charge as a beta version [27]. The program goal is to calculate the levels of electricity generation in renewable energy plants and to evaluate long-term scenarios. Specifically, the tool aims to determine ideal locations to access RES, such as urban PV.

Solarius PV is a paid software that uses Building Information Modeling (BIM) to design PV systems [28]. The program has the capacity to elaborate the 3D modeling of the PV system to be designed, calculate shading, and economically evaluate the project. In addition, the tool has a free trial license for one month and its databases include Metenorm or PV-GIS weather data and the libraries of modules, inverters and batteries according to the market.

SOLergo [29] is a paid program developed by the company Eletronic Graphics and is focused on the application of PV systems for the Brazilian market. The program allows simulations to be carried out with complete dimensioning of PV systems connected to the distribution network, disconnected or hybrid. The tool has the ability to generate technical, economic reports and electrical diagrams to be sent to the dealership.

Synergi Electric is a paid program developed by DNV GL capable of modeling and analyzing electricity distribution systems in real environments, considering details from the substation to the customer. The tool has the ability to simulate and evaluate scenarios using electrical and financial parameters, acquire data with customer's meters and works with the SCADA system [30].

Urbs is a free and open source program developed to model electric power systems in several areas and to optimize costs, allowing the creation of PV scenarios in urban environments, but focusing on energy demand, storage and intermittent supply [31].

WebOpt (Distributed Energy Resources Web Optimization Service) [32] is a tool focused on evaluating integrated energy systems, allowing to model and optimize energy scenarios under criteria of economic costs and $\mathrm{CO} 2$ emissions. WebOpt can perform: minimizing costs, minimizing $\mathrm{CO} 2$ emissions and multipurpose analysis, which is minimizing $\mathrm{CO} 2$ with cost restrictions.

The tools are gathered and summarized in Table 1.

Table 1 - Classification of tools

\begin{tabular}{|c|c|c|c|c|c|c|}
\hline \multirow{2}{*}{$\begin{array}{l}\text { Evaluated } \\
\text { Tools }\end{array}$} & \multicolumn{5}{|c|}{ Ratings } & \multirow{2}{*}{ References } \\
\hline & Simulation & Scenario & Bottom-Up & Availability & Urban PV & \\
\hline Balmorel & Yes & Yes & Yes & Free access & Yes & [13] \\
\hline CEA & Yes & Yes & Yes & Free access & Yes & [14] \\
\hline Dieter & Yes & Yes & Yes & Free access & No & [15] \\
\hline District ECA & Yes & Yes & No & Free access & No & [16] \\
\hline EnergyPlan & Yes & Yes & Yes & Free access & No & [17] \\
\hline EnergyPro & Yes & Yes & Yes & Paid & Yes & [18] \\
\hline Grid LAB-D & Yes & Yes & Yes & Free access & Yes & [19] \\
\hline Homer PRO & Yes & Yes & Yes & Paid & Yes & {$[20]$} \\
\hline HUES & Yes & Yes & Yes & Free access & Yes & [21] \\
\hline iHOGA & Yes & Yes & Yes & $\begin{array}{c}\text { Educational/ } \\
\text { Commercial Version }\end{array}$ & Yes & [22] \\
\hline Insel & Yes & No & No & Free access & Yes & [23] \\
\hline Oemof & Yes & No & Yes & Free access & Yes & [24] \\
\hline OSeMOSYS & Yes & Yes & Yes & Free access & No & {$[25]$} \\
\hline RETScreen & Yes & Yes & Yes & $\begin{array}{c}\text { Educational/ } \\
\text { Commercial Version }\end{array}$ & Yes & [26] \\
\hline SIREN & Yes & Yes & Yes & Free access & Yes & [27] \\
\hline Solarius PV & Yes & Yes & Yes & Paid & Yes & [28] \\
\hline SOLergo & Yes & Yes & Yes & Paid & Yes & [29] \\
\hline Synergi Electric & Yes & Yes & Yes & Paid & Yes & [30] \\
\hline Urbs & Yes & Yes & Yes & Free access & Yes & [31] \\
\hline WebOpt & Yes & Yes & Yes & Free access & Yes & [32] \\
\hline
\end{tabular}

\section{Results and Discussions}

\section{A. Evaluation Tools}

For the evaluation developed, less than half of the tools have all the features. Fig. 04 shows the number of functionalities each program has in green and in blue the criteria of availability, being assigned value 1 for free access and educational/commercial version and 0 for paid.
Balmorel, CEA, Grid LAB-D, HUES, iHOGA, RETScreen, SIREN, Urbs and WebOpt have the four features evaluated and have a free version; Energy Pro, HOMER PRO, Solarius PV, SOLergo and Synergi Electric also present all four, but have only paid version. The programs with the lowest rating are District ECA and Insel, since they have only two of the four features. 


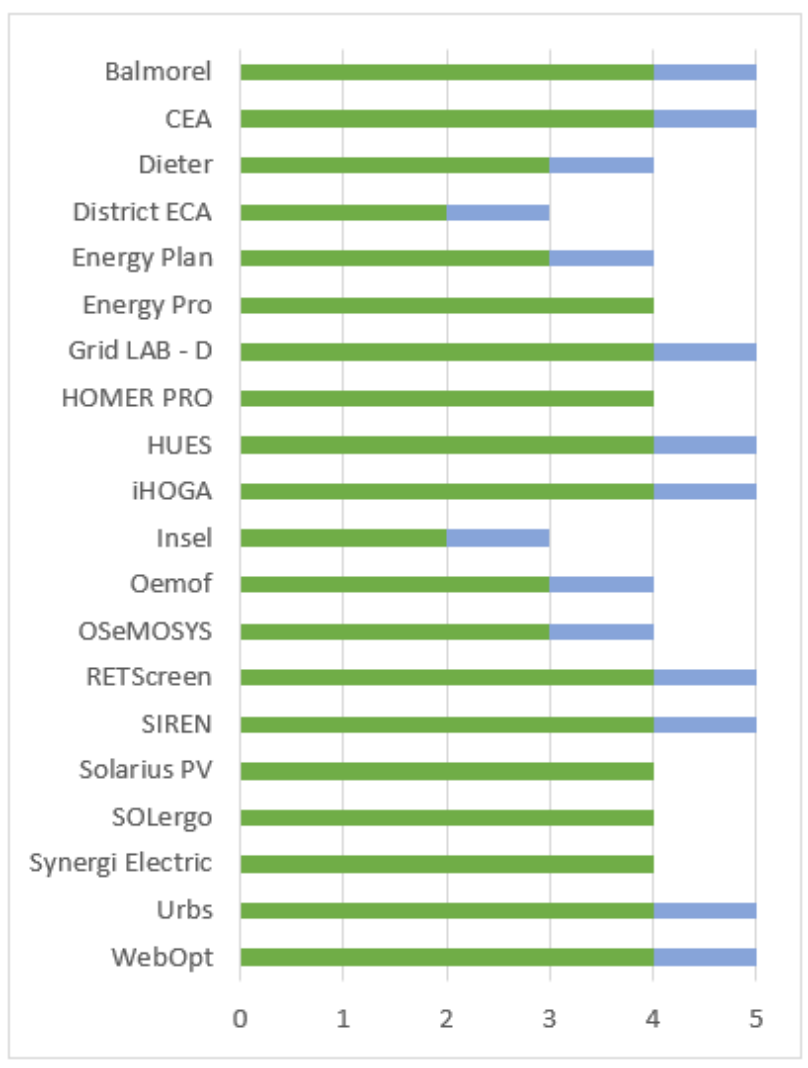

Fig.4. Quantitative of funcionalities

Evaluating the use of the tools, all have simulation capability. In the case of scenario generation, only Insel and Oemof do not have this application. For Bottom-Up, Dritrict ECA and Insel do not provide this assessment. For the case of Urban PV application, no apply in dieter, district eca, energyplan and osemosys, although they evaluate PV systems. Fig. 5 shows the number of tools each feature has.

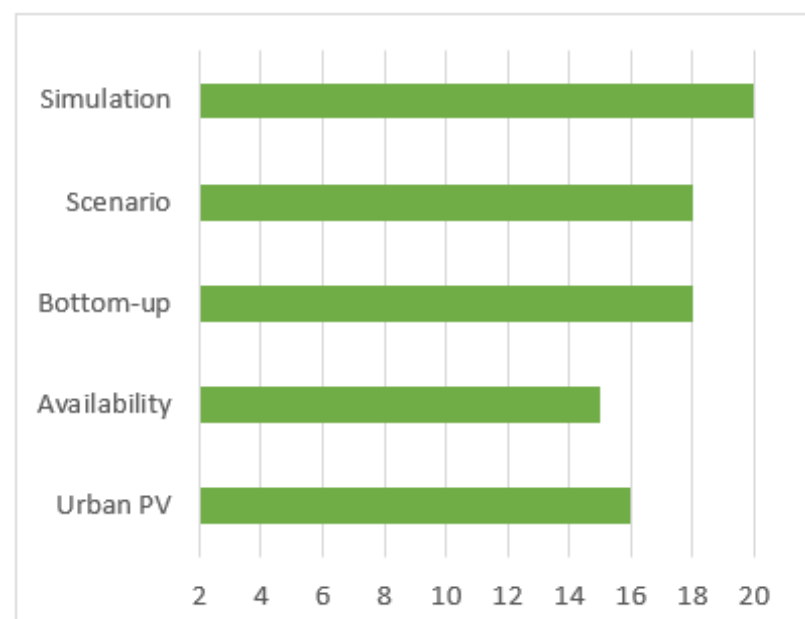

Fig.5. Quantitative of tools that each funcionality

\section{B. Evaluation Energetic}

According to the literature review, the applications of BAPV and BIPV were identified in the selected articles, meaning the need to understand the level of integration of the tools in scaling the PV system in isolation and to allow the addition of structural information to make the system integrated to the construction. Fig. 2 shows these data being classified as low or very low priority, since they are not the focus of the research.

With the exception of Dieter, District ECA and OSeMOSYS, all evaluated tools have sizing and energy planning capacity when the installation already exists and the system is designed later, that is, for the BAPV case. However none has complete integration in the BIPV, since a project with BIPV requires a structural analysis, adapting the materials to the construction of the system still in the elaboration phase.

Currently, structural projects are developed in programs such as AutoCAD, AutoCAD Civil 3D and SketchUp, but these do not have the capacity to develop BIPV. Differently, programs such as Revit and ArchCAD, which use BIM methodology, refer to the modeling of construction information deal exactly with this type of integrated project, since one of the bases of BIM is the energy modeling of the construction.

\section{Conclusion}

Our research assists in the identification of tools appropriate to energy planning from the urban PV point of view, whether free or paid. It can also be seen that we lack BIPV interaction programs.

In this sense, only the simulation feature was identified in all programs evaluated, and 16 of the 20 presented ability to evaluate urban PV. Thus, Balmorel, CEA, Grid LABD, HUES, iHOGA, RETScreen, SIREN, Urbs and WebOpt are highlighted by having all the features and being available free of charge to the community and Energy Pro, HOMER PRO, Solaruis PV, SOLergo and Synergi Electric as paid alternatives. Insel and District ECA are not suitable for this purpose.

In addition, for a fully integrated urban PV planning project, BIPV applications are an alternative to be considered and, consequently, the integration with the BIM methodology, which already exists as a trend to integrated projects between all building and energy elements.

\section{Acknowledgement}

FUNCAP for researcher scholarship awarded to the first autor and $\mathrm{CNPq}$ for researcher scholarship awarded to the third author.

\section{References}

[1] IRENA. International Renewable Energy Agency. <https://www.irena.org/costs/Charts/Solar-photovoltaic> [Accessed 18.02.21]

[2] ANEEL. Agência Nacional de Energia Elétrica. <https://www.aneel.gov.br/dados/geracao > [Accessed 18.02.21]

[3] ABSOLAR. Associação Brasileira de Energia Solar Fotovoltaica. <http://www.absolar.org.br/infograficoabsolar.html > [Accessed 18.02.21]

[4] Cajota, S., Peter, M.. Obstacles in energy planning at the urban scale, Sustainable Cities and Society 30 (2017) 223 236. https://doi.org/10.1016/j.scs.2017.02.003 
[5] Collaço, F.M., Simoes, S.G., Dias,L.P. The dawn of urban energy planning e Synergies between energy and urban planning for São Paulo (Brazil) megacity; Journal of Cleaner Production $215 \quad$ (2019) 458 e 479. https://doi.org/10.1016/j.jclepro.2019.01.013

[6] Creutzig, F., Agoston, P., Minx, J.C., Canadell, J.G., 2016. Urban infrastructure choices structure climate solutions. Nat. Clim. Change 6, 1054e1056. https://doi.org/10.1038/nclimate3169.

[7] Markovic D, Cvetkovic D and Masic B. Survey of software tools for energy efficiency in a community. Renewable and Sustainable Energy Reviews 2011;15(9):4897-903. https://doi.org/10.1016/j.rser.2011.06.014

[8] Tozzi P and Jo G H. A comparative analysis of renewable energy simulation tools: Performance simulation model vs. system optimization. Renewable and Sustainable Energy Reviews 2017;80:390-98

https://doi.org/10.1016/j.rser.2017.05.153

[9] Manfrem M, Caputo P and Costa G. Paradigm shift in urban energy systems through distributed generation: Methods and models. Applied Energy 2011;88(4):1032-48. https://doi.org/10.1016/j.apenergy.2010.10.018

[10] Connolly D, Lund H, Mathiesen B V and Leahy M. A review of computer tools for analysing the integration of renewable energy into various energy systems. Applied Energy https://doi.org/10.1016/j.apenergy.2009.09.026

[11] Ferrari S, Zagarella F, Caputo $\mathrm{P}$ and Bonomolo $\mathrm{M}$. Assessment of tools for urban energy planning. Energy 2019;176:544-51.

https://doi.org/10.1016/j.energy.2019.04.054

[12] IEA. International definitions of "BIPV". < https://ieapvps.org/wp-content/uploads/2020/02/IEA-

PVPS_Task_15_Report_C0_International_definitions_of_B IPV_hrw_180823.pdf> [Accessed 21.02.21]

[13] Balmorel. <http://www.balmorel.com/> [Accessed 09.01.21]

[14] Fonseca J A, Nguyen T, Schlueter A and Marechal F. City Energy Analyst (CEA): integrated framework for analysis and optimization of building energy systems in neighborhoods and city districts. Energy and Buildings 2016;113:202-26.

[15] Dieter. DIW Berlin. <http://www.energy-workshop.cz/pdfwednesday/zerrahn.pdf $>$ [Accessed 23.07.20]

[16] District ECA. Fraunhofer Institute for Building Physics IBP. <https://www.district-eca.de/index.php?>

[Accessed 23.01.21]

[17] EnergyPLAN. Sustainable Energy Planning Research Group. <https://www.energyplan.eu/> [Accessed 22.01.21]

[18] EnergyPRO. EMD International. <https://www.emd.dk/energypro/> [Accessed 21.01.21]

[19] GridLAB-D. U.S. Department of Energy (DOE). <https://www.gridlabd.org/> [Accessed 22.01.21]
[20] Lambert T, Gilman P and Lilienthal P. Micropower system modeling with HOMER. Integration of alternative sources of energy. 2006:379-418 https://doi.org/10.1002/0471755621.ch15

[21] HUES. <https://hues-platform.github.io/> [Accessed 21.01.21]

[22] IHoga. <https://ihoga.unizar.es/> [Accessed 22.01.21]

[23] Bernal-Agustín JL, Dufo-Lopez R. Efficient design of hybrid renewable energy systems using evolutionary algorithms. Energy Convers Manag 2009;50:479-89. https://doi.org/10.1016/j.enconman.2008.11.007

[24] Oemof. <https://oemof.org/> [Accessed 21.01.21]

[25] Howells M, Rogner H, Strachan N, Heaps C, Huntington H, Kypreos S, Hughes A, Silveira S, DeCarolis $\mathbf{J}$ and Bazillian M.. OSeMOSYS: the open source energy modeling system: an introduction to its ethos, structure and development. Energy Policy 2011;39:5850-70 https://doi.org/10.1016/j.enpol.2011.06.033

[26] RETScreen. Natural Resources Canada. $<$ https://www.nrcan.gc.ca/maps-toolspublications/tools/data-analysis-softwaremodelling/retscreen/7465> [Accessed 23.01.21]

[27] SIREN SEN. <https://www.sen.asn.au/modelling_overview> [Accessed 23.01.21]

[28] SOLergo. Electro Graphics. 〈https://www.electrographics.com.br/produtos/solergo> [Accessed 20.01.21]

[29] Solarius PV. ACCA Software <https://www.accasoftware.com/ptb/softwarefotovoltaico $>$ [Accessed 19.01.21]

[30] Synergi Electric <https://www.dnvgl.com/services/powerdistribution-system-and-electrical-simulation-softwaresynergi-electric-5005> [Accessed 23.01.21]

[31] Urbs. Universidade Técnica de Munique. <https://urbs.readthedocs.io/en/latest/index.html> [Accessed 23.01.21]

[32] Web Optimization Service (WebOpt). DER-CAM. $<$ https://china.lbl.gov/der-cam> [Accessed 21.01.21] 